\title{
Observed Decadal Transition in Trend of Autumn Rainfall over Central China in the Late 1990s
}

\author{
ZUNYA WANG \\ Collaborative Innovation Center on Forecast and Evaluation of Meteorological Disasters, Nanjing \\ University of Information Science and Technology, Nanjing, and National Climate Center, \\ China Meteorological Administration, Beijing, China
}

BOTAO ZHOU

\begin{abstract}
Collaborative Innovation Center on Forecast and Evaluation of Meteorological Disasters/Key Laboratory of Meteorological Disaster, Ministry of Education, and School of Atmospheric Sciences, Nanjing University of Information Science and Technology, Nanjing, and Laboratory for Climate Studies, National Climate Center, China Meteorological Administration, Beijing, China
\end{abstract}

(Manuscript received 28 February 2018, in final form 9 December 2018)

\begin{abstract}
This article presents a decadal transition from a decreasing trend to an increasing trend in the late 1990s for autumn rainfall in central China. The atmospheric and oceanic background underlying this regime shift is also addressed. Accompanying the above decadal transition, the moisture convergence and ascending motion averaged in central China both switch from a weakening trend to a strengthening trend. Meanwhile, after the late 1990s, the declining of the Asian sea level pressure (SLP) and the deepening of the Lake Balkhash trough may induce more cold air from high latitudes to break out southward. The strengthening of the low-level southerly in East Asia could transport more moisture northward from low latitudes. More cold air and more warm-moist airflow encountering in the targeted region contribute to the increasing trend of local rainfall. The situation before the late 1990s is generally reversed, which accounts for the decreasing trend of autumn rainfall. The movement of the East Asian jet (EAJ) from southward to northward also has a contribution via its influence on dynamic condition. Additionally, changes in the sea surface temperatures (SSTs) in the western Indian and Atlantic Oceans from a cooling trend to a warming trend in the late 1990s play significant roles through their modulations on moisture transport and cold-air activities.
\end{abstract}

\section{Introduction}

Precipitation change is a topic of particular interest and concern, since droughts and floods resulting from anomalous precipitation often exert severe impacts on the socioeconomic development. Given that China suffers from frequent floods and persistent droughts simultaneously but in different regions, much research has been devoted to the long-term variation of precipitation in China.

There is evidence that summer precipitation in East China has had apparent decadal variations since the second half of the twentieth century. One decadal shift

๑ Denotes content that is immediately available upon publication as open access.

Corresponding author: Botao Zhou, zhoubt@cma.gov.cn occurred in the late 1970s, with more precipitation in the Yangtze River valley and less precipitation in North China (e.g., Wu and Chen 1998; Gong and Ho 2002; Ding et al. 2008; Qian and Qin 2008; Zhao et al. 2010). This precipitation regime shift may be attributed to the weakening of the East Asian summer monsoon (Wang 2001; Gong and Ho 2002; Yu et al. 2004; Ding et al. 2008; Zhao et al. 2011; Wang et al. 2013), changes in sea surface temperature (SST; Hu 1997; Chang et al. 2000; Li and Xian 2003; Yang and Lau 2004; Lu et al. 2006; Ma 2007; Li et al. 2008; Fu et al. 2009), an increase in Tibetan Plateau snow (Zhang et al. 2004; Ding et al. 2009; Zhao et al. 2010), and a decrease in Eurasian snow cover (Liu and Yanai 2002; Zhang et al. 2008; Wu et al. 2009).

Since the late 1990s, the summer rain belt in East China has moved northward, resulting in an increase of precipitation in the Yellow River-Huaihe River valley and a decrease in precipitation in the Yangtze River 
valley (Zhu et al. 2011; Huang et al. 2013; Xu et al. 2015). The increase of precipitation in the Yellow RiverHuaihe River valley may link to the warming over Lake Baikal and the weakening of the East Asian jet (EAJ), which are probably induced by the shift of the Pacific decadal oscillation (PDO) from a positive phase to a negative phase. The eastward recession of the western Pacific subtropical high may account for the decrease of precipitation in the Yangtze River valley (Zhu et al. 2011). The increase of summer precipitation in South China after 1992/93 is also identified (Yao et al. 2008; Ding et al. 2009; Wu et al. 2010; Fan et al. 2014; Xu et al. 2015). Wu et al. (2010) proposed that the snow cover expansion in the Tibetan Plateau and the SST warming in the equatorial Indian Ocean may explain such an increase. In addition, Huang et al. (2017) found that winter precipitation has increased in northern China and decreased in southern China since the late 1990s. They attributed these changes to the equatorward (poleward) shift of the East Asian polar front jet (the East Asian subtropical jet), which may result from the combined effect of a negative phase of the interdecadal Pacific oscillation (IPO) and a positive phase of the Atlantic multidecadal oscillation (AMO).

These findings have greatly enriched our knowledge on the decadal change in the precipitation regime of China. However, relatively less attention has been paid to the autumn season. As is known, autumn rainfall, a typical climate phenomenon in the central part of China, is characterized by the second peak of local precipitation amount (Gao and Guo 1958; He 1984; Liang 1989; Ding and Wang 2008) and regarded as the last rainy stage that is associated with the advance and retreat of the East Asian summer monsoon (Ding 2007; Ding and Wang 2008; Yuan and Liu 2013). The number of autumn rainy days and the percentage of autumn precipitation amount relative to annual amount are also the greatest across China (Fig. 1). Anomalous variations of autumn precipitation in this region usually give rise to droughts, floods, and secondary disasters, which bring great damage to agriculture and cause enormous economic losses. Thus, the change in autumn rainfall is also a critical issue.

Previous studies have documented some factors that have influences on the variability of autumn rainfall in the western and central parts of China, such as the Eurasian pattern, the western Pacific subtropical high, the Indian-Burmese trough (Bao et al. 2003; Chen and Shi 2003; Bai and Dong 2004; Liu et al. 2012; Luo et al. 2013), the heating over the Tibetan Plateau (Chen et al. 2001), El Niño-Southern Oscillation (ENSO), Indian Ocean dipole (IOD), and PDO (Liu and Yuan 2006; Wang et al. 2015; Xu et al. 2016; Qin et al. 2018). In

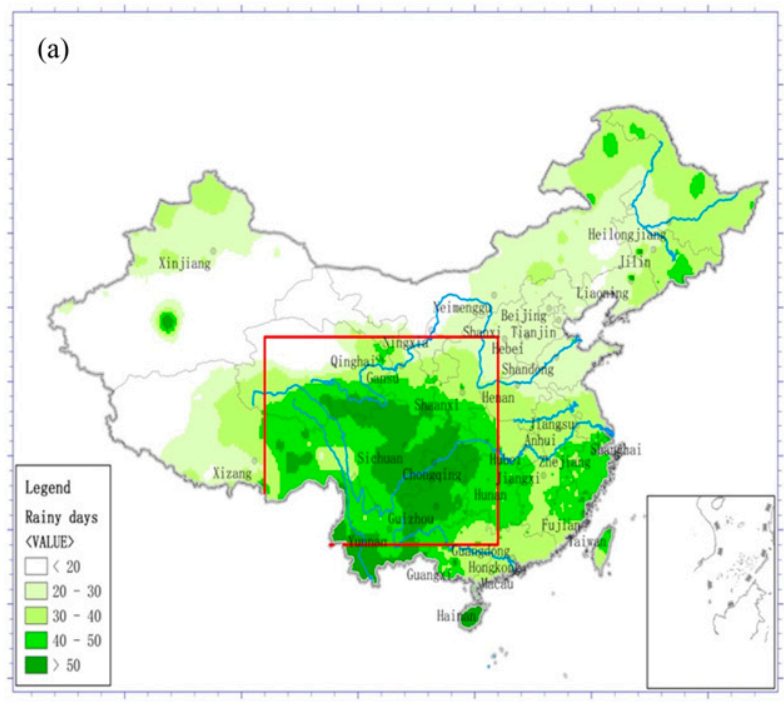

(b)

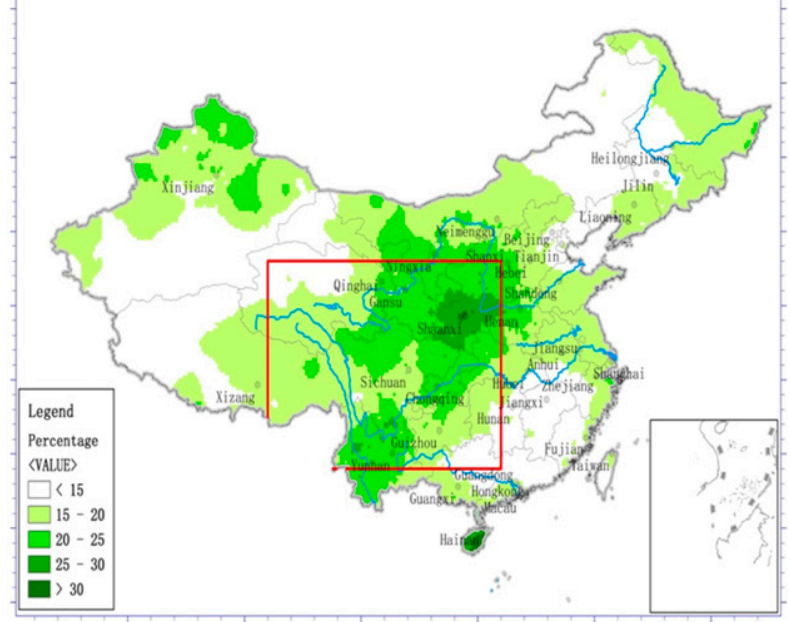

FIG. 1. (a) The number of rainy days in autumn (SeptemberNovember) and (b) the percentage of autumn precipitation amount relative to annual precipitation amount for the climatology of $1961-2016$. The central China domain $\left(24^{\circ}-38^{\circ} \mathrm{N}, 92^{\circ}-112^{\circ} \mathrm{E}\right)$ is outlined by red lines.

addition, some studies revealed that autumn rainfall in the central part of China shows a decreasing trend under the background of climate change (Bai and Dong 2004; Jiang et al. 2014; Zhang et al. 2018). Nevertheless, in analyzing its long-term change, we noticed that there also exists a decadal transition in the late 1990s for the trend of autumn rainfall. The present study documents this decadal transition and attempts to understand the roles of the atmospheric circulations and SSTs.

The reminder of this paper is organized as follows. Section 2 describes the data and methods used in this study. Section 3 presents the decadal transition in trend 
of autumn precipitation in the central part of China. The associated changes in local moisture and dynamic conditions and large-scale atmospheric circulations are analyzed in section 4. The roles of the SSTs in the Indian Ocean and the Atlantic Ocean are examined in section 5. The major findings are summarized in section 6 .

\section{Data and methods}

The daily precipitation dataset for the period of 1961-2016 from 2419 meteorological stations in China, compiled by the National Meteorological Information Center of China Meteorological Administration (CMA) after quality control, is used in this study. Among these stations, there are 212 national reference stations, 632 national basic stations, and 1575 national meteorological observing stations. The original daily precipitation data were collected from version 3.0 of the Fundamental Elements Datasets of the China National Stations. The quality-control procedures applied include checks and corrections for climatological, station, and regional outliers and for internal, temporal, and spatial consistency (Cao et al. 2016). In the current study, we focus on the domain $24^{\circ}-38^{\circ} \mathrm{N}, 92^{\circ}-112^{\circ} \mathrm{E}$, which is outlined in Fig. 1 and referred to as central China for its location. Before the analysis, we eliminated the stations with the ratio of missing records to the total records higher than $1 \%$ during autumn (September-November) of 19612016, leaving a total of 524 stations for use. For these stations, the missing daily records were filled by climatological values of daily precipitation during 1961-2016. The regional mean precipitation for central China is calculated using the area-weighted average because of the sparse distribution of stations in its western part.

The daily atmospheric reanalysis data at $2.5^{\circ} \times 2.5^{\circ}$ provided by the National Centers for Environmental Prediction-National Center for Atmospheric Research (NCEP-NCAR; Kalnay et al. 1996) and the monthly SST data at $2^{\circ} \times 2^{\circ}$ (Smith and Reynolds 2004) from the National Oceanic and Atmospheric Administration (NOAA) are also used.

The methods adopted mainly include regression analysis and correlation analysis. The linear trend is estimated with the least squares method. Detrending of the data in this study means that the linear trend over the entire period of 1961-2014 is removed. The decadal component of time series is extracted through the Fourier harmonics by keeping periods longer than 10 years. The statistical significance is determined using the Student's $t$ test. As a meteorological variable may not be independent from others for the decadal component obtained by filtering, the effective sample size is applied for the significance test of correlation between two time
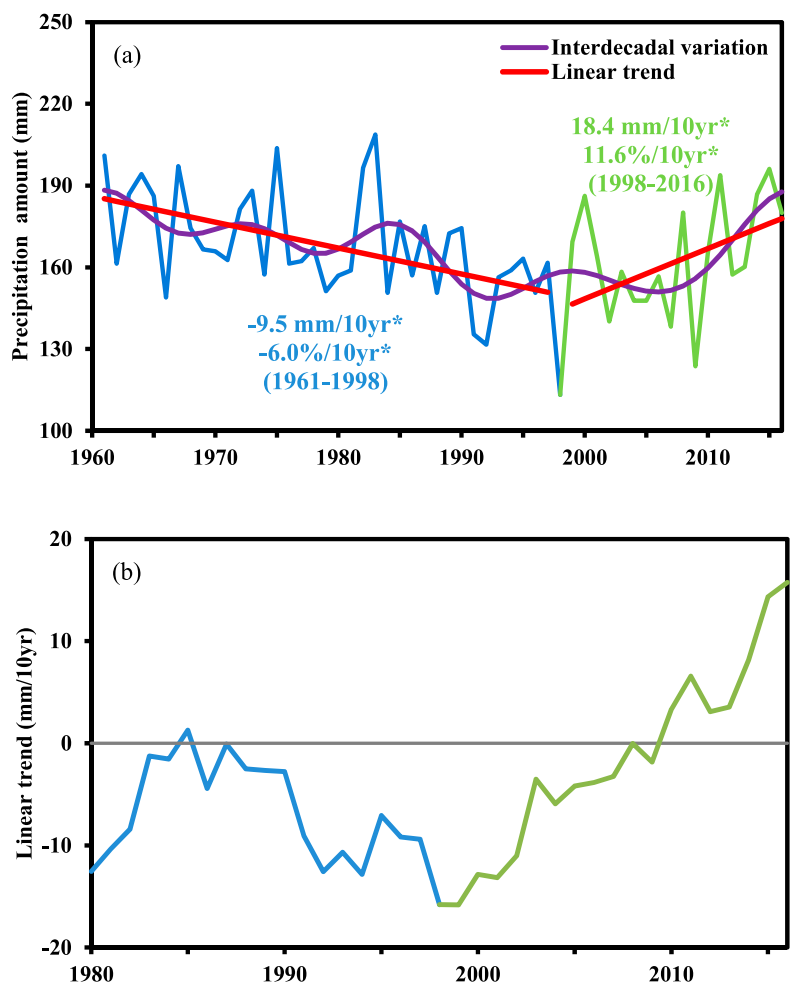

FIG. 2. (a) Time series of the autumn precipitation averaged over central China from 1961 to 2016 (blue line for 1961-98; green line for 1998-2016). The values indicate the trends in the two periods, and the asterisk indicates significance at the $95 \%$ level. (b) Linear trends of the autumn precipitation averaged over central China with a 20-yr sliding window for the period of 1961-2016 (blue line for 1980-98; green line for 1998-2016). The year on the abscissa indicates the last year of the window (i.e., 1980 labels the period 1961-80).

series $x(t)$ and $y(t)$ on the interdecadal time scale, in terms of the equation (Davis 1976; Bretherton et al. 1999)

$$
N^{*}=\frac{N}{\sum_{\tau=-(N-1)}^{N-1}(1-|\tau| / N) \rho_{x}(\tau) \rho_{y}(\tau)},
$$

where $N^{*}$ is the effective sample size, and $\rho_{x}(\tau)$ and $\rho_{y}(\tau)$ are the autocorrelation functions of $x(t)$ and $y(t)$, respectively.

\section{Decadal transition of the trend in autumn rainfall over central China}

Figure 2a shows the temporal variation of autumn precipitation averaged over central China during 1961-2016. Besides the interannual and interdecadal variability, a transition of the trend occurred in the late 1990s. During the former period (1961-98), the autumn precipitation shows a significantly decreasing trend at a rate of 
$9.5 \mathrm{~mm} \mathrm{decade}^{-1}$ ( $6 \%$ decade $^{-1}$ relative to the seasonalmean climatology). During the latter period (1998-2016), however, it exhibits a significantly increasing trend with the rate of $18.4 \mathrm{~mm} \mathrm{decade}^{-1}\left(11.6 \%\right.$ decade $^{-1}$ relative to the seasonal-mean climatology). The transition in the late 1990s can also be detected in the running series of the linear trend with a 20-yr window for the period of 19612016. As shown in Fig. 2b, the negative trend reaches the maximum in 1998, after which it begins to weaken gradually and then shifts to a positive trend around 2010 . As trends based on short records are sensitive to the beginning and end dates, the persistent weakening of the negative trends for a 20-yr window, to some extent, indicates a gradual recovery of precipitation after 1998 despite the fact that the 20 -yr trend is still negative until about 2010. In fact, the trend change is a reflection of the oscillation with low values from the early 1990s to around 2010 and higher values before the early 1990s and after about 2010; the minimum value appeared in 1998 (purple line in Fig. 2a).

Different from the change of the precipitation amount, no appreciable transition is found in the trend of rainy days (Fig. 3). Both before and after the late 1990s, the number of rainy days shows a downward trend, with their respective rates being $-8.1 \%$ and $-4.4 \%$ decade $^{-1}$. Over the course of the whole period, the rainy days decrease at a rate of $6.3 \%$ decade $^{-1}$. Through comparing Figs. 3 and $2 \mathrm{a}$, one can deduce that the increase in precipitation amount after the late 1990s is mainly caused by the increase in precipitation intensity, since the trends of the amount and frequency are opposite. In other words, the precipitation intensity has strengthened in recent two decades.

Further, we divide the rainfall events according to the CMA's classification into four categories: light rainfall $\left(0.1-9.9 \mathrm{~mm} \mathrm{day}^{-1}\right)$, moderate rainfall $(10-24.9 \mathrm{~mm}$ day $\left.^{-1}\right)$, large rainfall $\left(25-49.9 \mathrm{~mm} \mathrm{day}^{-1}\right)$, and heavy rainfall $\left(>50 \mathrm{~mm} \mathrm{day}^{-1}\right)$. The contributions of the four categories to the total autumn rainfall can be quantified by the percentages of the seasonal total. In general, the light rainfall events explain the largest fraction of the total autumn rainfall, showing a contribution of $37 \%$ to the total amount and $88 \%$ to the total frequency. The contributions to the total autumn rainfall amount (frequency) from the moderate, large, and heavy rainfall events are $34 \%(9 \%), 19 \%$ (2\%), and $10 \%$ (1\%), respectively.

The temporal changes of the light-to-heavy rainfall events during 1961-2016 are examined in terms of their amounts and frequencies. Seen from Fig. 4, the trends in the amounts of the four categories of events display a uniform transition in the late 1990s, having previously been negative before progressing into positive after that time. Such a decadal transition is in good agreement

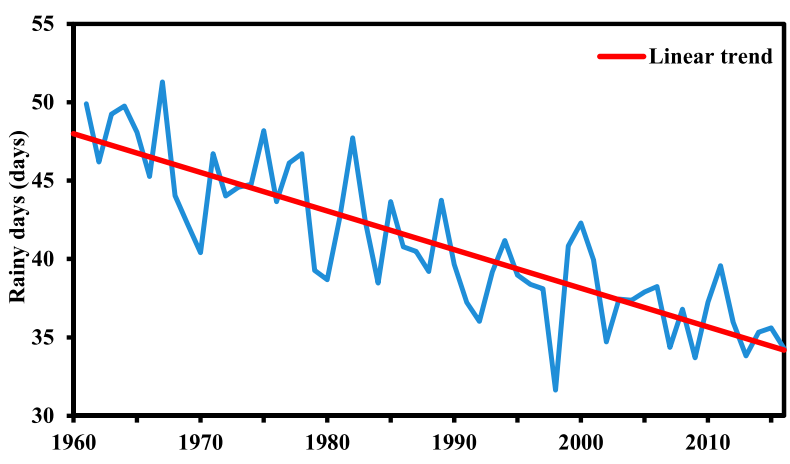

FIG. 3. Time series of the rain days averaged over central China from 1961 to 2016.

with that for the trend of the total amount. Furthermore, the rainfall events with greater intensity delineate relatively larger and more significant increasing rates in the latter period (1998-2016). During the former period (1961-98), the decreasing amplitudes are generally comparable for the four categories. This evidence demonstrates that changes in the light to heavy rainfall amounts all contribute positively to the trend transition of the total amount.

However, the frequencies of the four categories of rainfall events feature different long-term changes. To be specific, the number of light rainfall events has decreased during the entire study period, while the moderate to heavy rainfall days present downward trends before the late 1990s and upward trends after the late 1990s. The consistent decreasing tendency between the light rainfall days and the total rainy days implies a prime contribution to the decrease of the total rainy days from the change in light rainfall events. The positive trends in the moderate to heavy rainfall events, with larger increasing rates corresponding to much stronger categories since the late 1990s, hint at more frequent occurrences of intense precipitation across the precipitation distribution, thereby resulting in an enhancement of the mean intensity of autumn precipitation.

Overall, the aforementioned result illustrates the fact that the autumn precipitation amount in central China experienced a decadal transition from a decreasing trend to an increasing trend in the late 1990s. In the following analysis, we explore the physical mechanism associated with this regime shift from the perspective of changes in atmospheric circulations and SSTs.

\section{Changes of the atmospheric background}

\section{a. Local moisture and dynamic conditions}

Moisture supply is essential to the occurrence of precipitation. Higher moisture convergence is more beneficial 

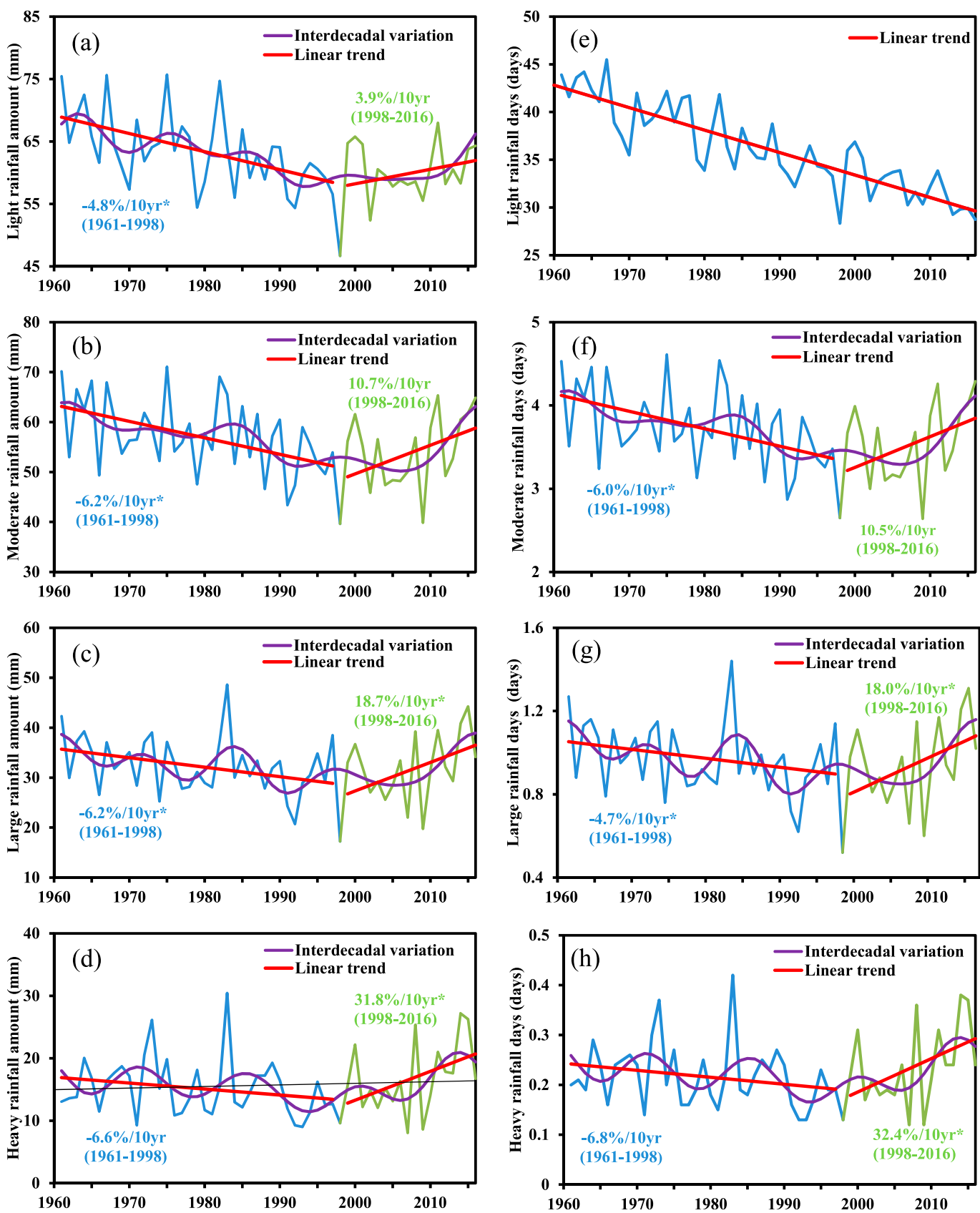

FIG. 4. Time series of the (left) amounts and (right) frequencies for different categories of rainfall events: (a),(e) light, (b),(f) moderate, (c),(g) large, and (d),(h) heavy rainfall averaged over central China from 1961 to 2016 (blue line for 1961-98; green line for 1998-2016). The values indicate the trends in the two periods, and the asterisk indicates significance at the $95 \%$ level.

for the increasing precipitation, and vice versa. Hence, we first investigate the secular change of the moisture convergence. Figure 5a plots the time series of the divergence of the moisture flux integrated vertically from 1000 to $300 \mathrm{hPa}$ over central China during autumn, which was calculated based on the specific humidity and horizontal winds from the daily reanalysis data.
Note that the negative value represents a convergence of the moisture flux. Accompanying the decadal transition of the trend in autumn precipitation, the divergence of the moisture flux also takes on a reverse change (i.e., a significant positive trend before the late 1990s and a significant negative trend after the late 1990s). The positive trend in the former period 

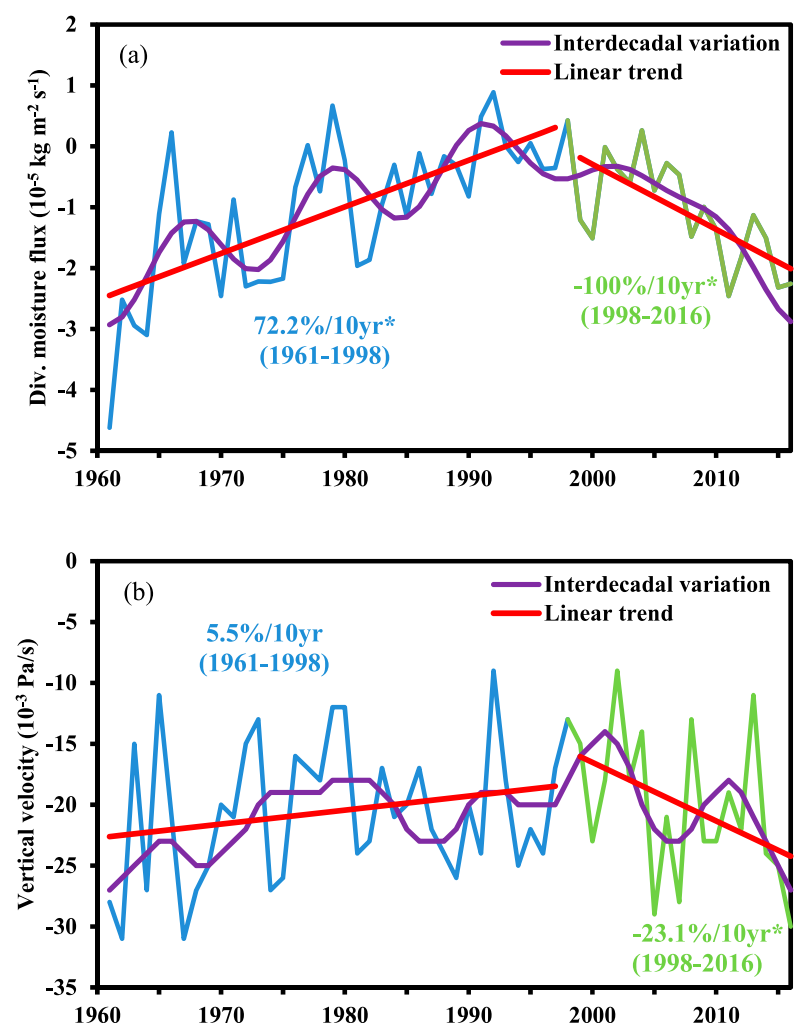

FIG. 5. Time series of (a) divergence of water vapor transport flux vertically integrated from 1000 to $300 \mathrm{hPa}$ and (b) 500-hPa vertical velocity averaged over central China from 1961 to 2016.

indicates a weakening of the moisture convergence, thus decreasing the autumn precipitation in central China. In the latter period, the negative trend indicating an enhancement of the moisture convergence favors the increase of autumn precipitation locally. The close relationship between the divergence of the moisture flux and the autumn rainfall in central China can be proven by the index correlation. As shown in Table 1, the correlations between them are -0.62 and -0.60 (significant at the $99 \%$ level) before and after detrending, respectively. Their correlation on the interdecadal time scale is -0.76 , also significant at the $99 \%$ level (Table 1).

The mean vertical velocity at $500 \mathrm{hPa}$ (negative values represent ascending motions), as a necessary dynamic requirement for the occurrence of precipitation, is observed to change from a weakening trend to a strengthening trend in central China (Fig. 5b). During the latter period (1998-2016), the vertical velocity is intensified at a rate of $23.1 \%$ decade $^{-1}$. This significant intensification of the ascending motion is assumed to enhance the autumn precipitation through catalyzing the development of local atmospheric convection. The situation is reversed during the former period (1961-98). The correlations between the 500-hPa vertical velocity and the autumn rainfall in central China are -0.53 before detrending, -0.56 after detrending, and -0.64 for the interdecadal components, all exceeding the $99 \%$ significance level (Table 1).

Therefore, the transition of the trend in autumn rainfall over central China is closely linked to the changes in both moisture convergence and ascending motion. Their tendency toward intensification since the late 1990s provides a favorable background for the increase of autumn precipitation in central China.

\section{b. Large-scale atmospheric circulations}

To figure out key large-scale atmospheric circulations in the lower and upper troposphere that may exert significant impacts on autumn rainfall in central China, the anomalies in sea level pressure (SLP), 500-hPa geopotential height, $850-\mathrm{hPa}$ horizontal winds, and $200-\mathrm{hPa}$ zonal wind regressed upon the autumn precipitation averaged over central China (Fig. 6) are analyzed.

The SLP regression distribution reveals that associated with the above-normal precipitation is a dominant negative-positive-negative pattern from the polar region to Asia via Europe (Fig. 6a). A similar spatial pattern can also be detected in 500-hPa geopotential

TABLE 1. Correlation coefficients between the autumn rainfall in central China and the indices of atmospheric circulations and SST. Note that one asterisk and two asterisks denote the $95 \%$ and $99 \%$ confidence levels, respectively. The effective sample size is presented in parentheses.

\begin{tabular}{lcrr}
\hline \hline \multirow{2}{*}{\multicolumn{1}{c}{ Indices }} & \multicolumn{2}{c}{ Autumn rainfall in central China } \\
\cline { 2 - 4 } & Original time series & Linear trends removed & Interdecadal component \\
\hline Divergence of moisture flux & $-0.62^{* *}$ & $-0.60^{* *}$ & $-0.76(11)^{* *}$ \\
500-hPa vertical velocity & $-0.53^{* *}$ & $-0.56^{* *}$ & $-0.64(30)^{* *}$ \\
V850 index & $0.60^{* *}$ & $0.56^{* *}$ & $0.83(11)^{* *}$ \\
U200 index & $-0.35^{* *}$ & $-0.32^{*}$ & $-0.38(11)$ \\
SLP index & $-0.43^{* *}$ & $-0.36^{* *}$ & $-0.74(9)^{* *}$ \\
Lake Balkhash trough index & $-0.63^{* *}$ & $-0.64^{* *}$ & $-0.79(20)^{* *}$ \\
WIO-SST - SEIO-SST & $0.31^{* *}$ & $0.29^{*}$ & $0.60(17)^{* *}$ \\
WAO-SST - EAO-SST & $0.45^{* *}$ & $0.47^{* *}$ & $0.59(20)^{* *}$ \\
\hline
\end{tabular}


(a) Reg. SLP on Pre.
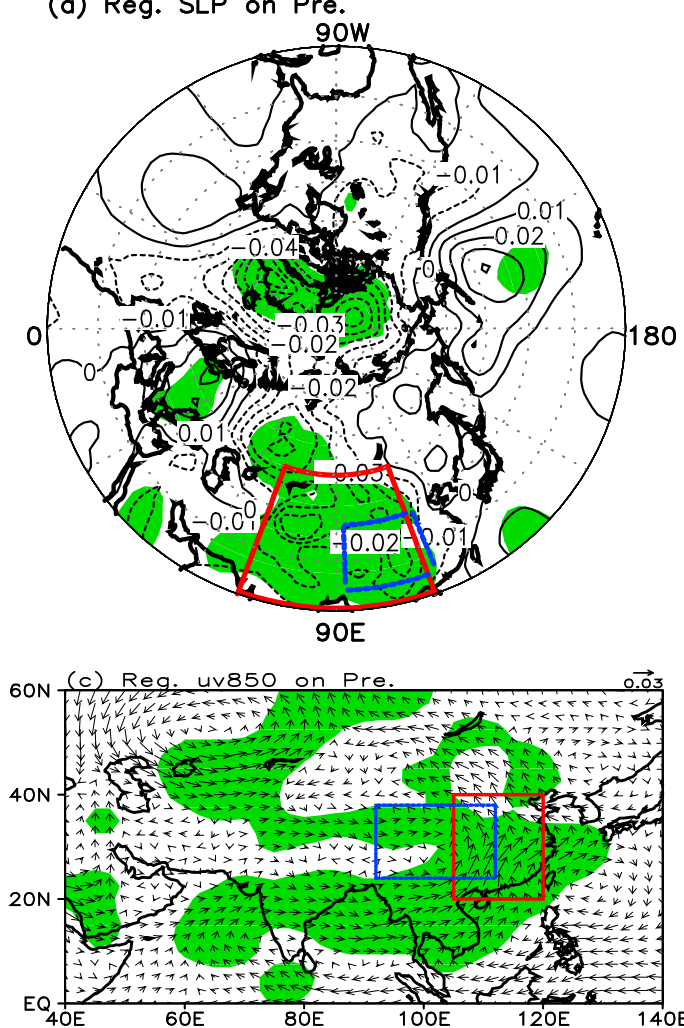

(b) Reg. H500 on Pre.

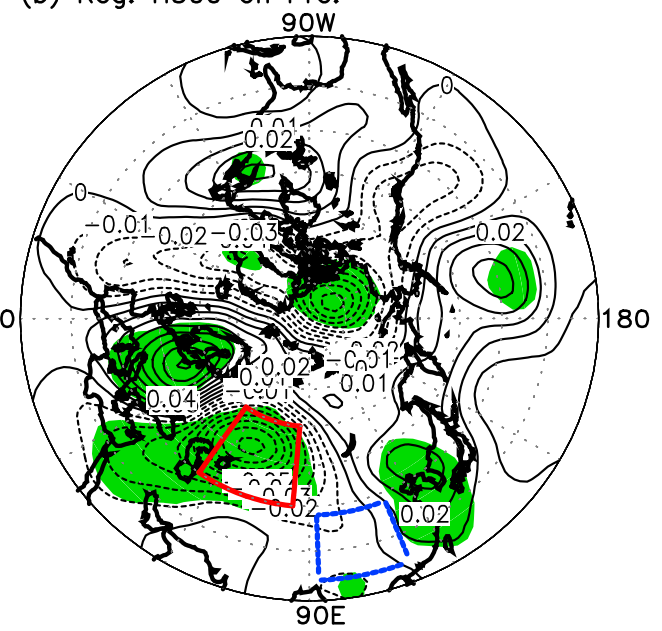

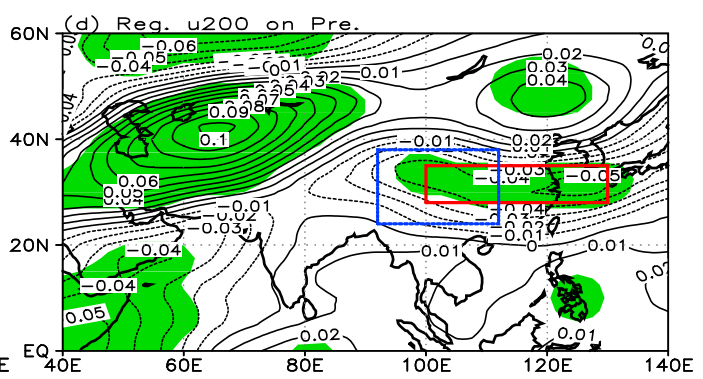

FIG. 6. Regressions of (a) SLP $\left(\mathrm{Pa} \mathrm{mm}^{-1}\right)$, (b) 500-hPa geopotential height $\left(10 \mathrm{~m} \mathrm{~mm}^{-1}\right)$, (c) 850-hPa horizontal winds $\left(\mathrm{m} \mathrm{s}^{-1} \mathrm{~mm}^{-1}\right)$, and (d) 200-hPa zonal wind $\left(\mathrm{m} \mathrm{s}^{-1} \mathrm{~mm}^{-1}\right)$ against the autumn precipitation averaged over central China during 1961-2016. All data were detrended before calculating. Regions above the $95 \%$ significance level are shaded. The key regions selected for the definition of the circulation indices are outlined by the red line, and the central China domain is outlined by the blue line.

height, showing a quasi-equivalent barotropic structure (Fig. 6b). The anomalous ridge over Europe and anomalous trough over Lake Balkhash may lead to much broader meridional meanders in the atmospheric circulation, conducive to a southward outbreak of cold air. Under the influence of the Lake Balkhash trough and the low-pressure anomaly in Asia, cold air is more prone to invade China through the west path.

In the low latitudes, an anticyclonic circulation anomaly dominates the lower troposphere of the Arabian Sea to the Bay of Bengal. The prevalent westerly anomalies advance northeastward gradually and turn to southerly anomalies in East Asia (Fig. 6c). As a consequence, the water vapor over the ocean can be transported toward the targeted region. The warm, moist airflow from the low latitudes encountering the cold air from the high latitudes in central China is favorable for the increase of local precipitation.

At $200 \mathrm{hPa}$ (Fig. 6d), the easterly anomaly is predominantly south of $\sim 35^{\circ} \mathrm{N}$ in East Asia, indicating a weakening of the westerly airflow. The westerly anomaly is dominant to the north, indicating a strengthening of the westerly airflow. This pattern suggests a northward displacement of the EAJ, since the climatological location of the EAJ core is located at $\sim 35^{\circ} \mathrm{N}$. The EAJ location is known to play a dynamical role in the precipitation variability, with the ascending motion to the right-hand side of the jet axis. Thus, the northward shift of the EAJ is also a favorable background for more precipitation in central China.

Based on the above analysis, four key circulation indices are selected:

The SLP index and the Lake Balkhash trough index, measured by the SLP averaged over the region $20^{\circ}-50^{\circ} \mathrm{N}, 75^{\circ}-110^{\circ} \mathrm{E}$, and the $500-\mathrm{hPa}$ geopotential height averaged over the region $40^{\circ}-60^{\circ} \mathrm{N}, 55^{\circ}-85^{\circ} \mathrm{E}$ to describe the activity of cold air.

The V850 index, defined as the area-averaged meridional wind at $850 \mathrm{hPa}$ over the region $20^{\circ}-40^{\circ} \mathrm{N}, 105^{\circ}-120^{\circ} \mathrm{E}$ to embody the transport of warm, moist airflow.

The U200 index, defined as the area-averaged zonal wind at $200 \mathrm{hPa}$ over the region $28^{\circ}-35^{\circ} \mathrm{N}, 100^{\circ}-$ $130^{\circ} \mathrm{E}$, to reflect the southward-northward displacement of the EAJ. 

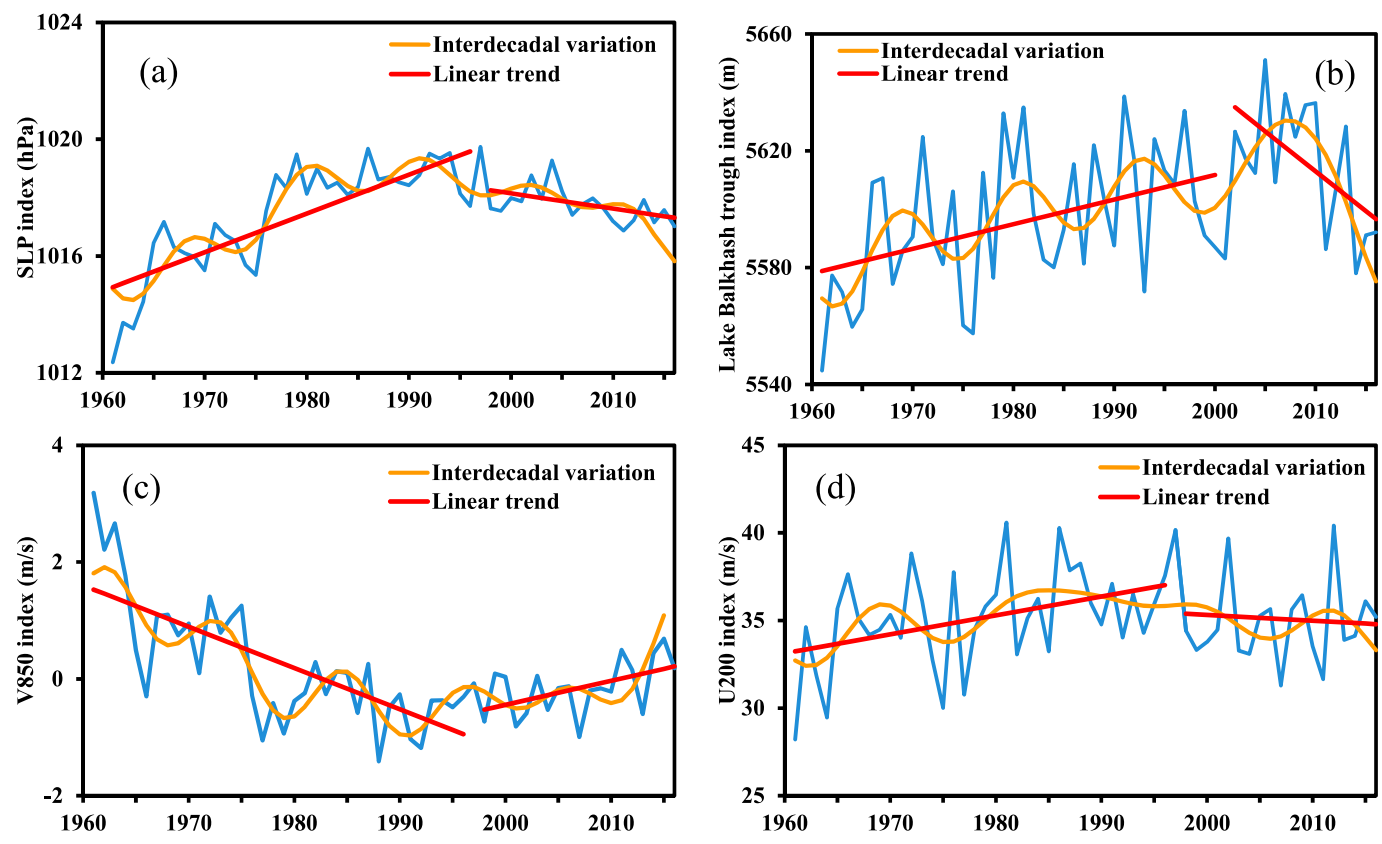

FIG. 7. Time series of four circulation indices from 1961 to 2016.

All four indices are significantly correlated to autumn rainfall in central China, whether their linear trends are removed or not (Table 1 ).

The temporal variations of the four indices from 1961 to 2016 are presented in Fig. 7. It can be observed that their trends also manifest decadal transitions sooner or later. The SLP index shifting from the significantly increasing trend to the significantly decreasing trend is pronounced in the late 1990s. The Lake Balkhash trough index shows a significant downward trend after 2000 , before which a significant upward trend is noticed. The V850 index also turns to the significant positive trend in the late 1990s from the significant negative trend. These changes suggest that the southward outbreak of cold air from high latitudes and the moisture transport from low latitudes have been enhanced since the late 1990s. More cold air and more warm, moist airflow entering central China may result in an increase of local precipitation. On the interdecadal time scale, the correlations of autumn rainfall in central China with the SLP index, the Lake Balkhash trough index, and the V850 index are $-0.74,-0.79$, and 0.83 (higher than the $99 \%$ significance level), respectively. The U200 index varies from a significantly strengthening trend to a slightly weakening trend in the late 1990s. It shows a movement of the EAJ from the south to the north of its normal position and thus provides a more advantageous dynamical background for the autumn precipitation over central China. Therefore, the combination of the above changes is concluded to account for the trend transition of the autumn precipitation in central China.

\section{Roles of the SSTs}

Having examined the simultaneous relationships between the SSTs and the autumn precipitation in central China, we found that the remarkable correlation regions are mainly located in the Indian Ocean and the Atlantic Ocean. Thus, the roles of the SSTs in these two regions are analyzed.

\section{a. Indian Ocean SST}

Figure 8 displays the correlations of the SST in the Indian Ocean with the autumn precipitation averaged in central China for the period 1961-2016. A dipole pattern, which is similar to the positive IOD phase (Saji et al. 1999), can be explicitly seen. The western Indian Ocean is dominated by the positive correlations, and the southeastern Indian Ocean is dominated by the negative correlations.

To facilitate analysis, the western Indian Ocean SST index (WIO-SST) and the southeastern Indian Ocean SST index (SEIO-SST) are defined as the mean SST averaged over the regions $10^{\circ} \mathrm{S}-10^{\circ} \mathrm{N}, 65^{\circ}-85^{\circ} \mathrm{E}$ and $10^{\circ} \mathrm{S}-0^{\circ}, 100^{\circ}-125^{\circ} \mathrm{E}$, respectively. Their arithmetic difference (i.e., WIO-SST minus SEIO-SST) is used to represent the dipole SST pattern. The correlations of this dipole pattern with the autumn rainfall in central China before and after detrending are 0.31 and 0.29 


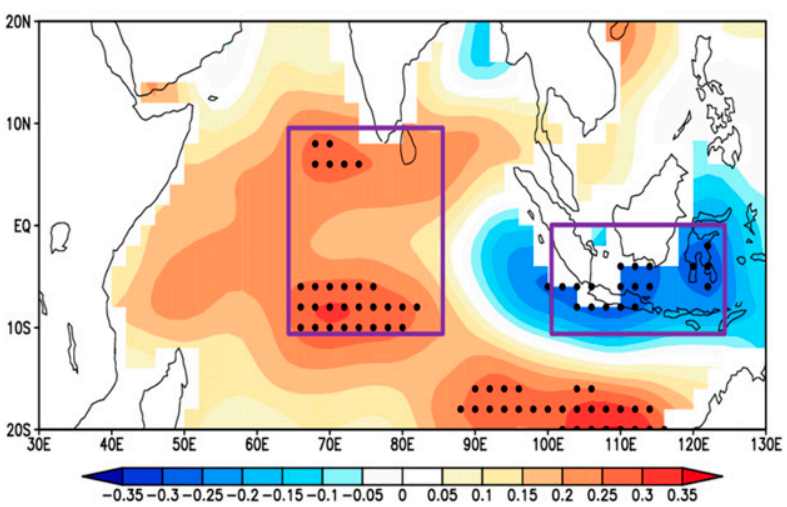

FIG. 8. Correlations between the SST in the Indian Ocean and the precipitation averaged over central China during autumn of 1961-2016. All data were detrended before calculating. Regions above the $95 \%$ significance level are marked by dots.

(both significant at the $95 \%$ level), respectively. Their correlation for the interdecadal components reaches 0.60 , higher than the $99 \%$ significance level (Table 1).

Figure $9 \mathrm{a}$ shows the $850-\mathrm{hPa}$ horizontal wind anomalies regressed upon the difference between WIO-SST and SEIO-SST. Corresponding to the pattern with above-normal SST in the western Indian Ocean and below-normal SST in the eastern Indian Ocean, anomalous easterlies prevail in the lower troposphere of the tropical Indian Ocean to the Maritime Continent, concomitant with anomalous anticyclonic circulations on either side of the equator. These atmospheric anomalies as a response to the anomalous SST may be linked by the local Walker circulation ( $\mathrm{Li}$ and $\mathrm{Mu}$ 2001; Guan and Yamagata 2003). As shown in Fig. 9b, airflow ascends in the western Indian Ocean due to the relatively warmer SST and subside in the southeastern Indian Ocean due to the relatively colder SST. To close the circuit, the easterly and westerly anomalies are formed in the lower and upper troposphere, respectively. The anticyclonic circulation anomalies north of the equator (Fig. 9a) can drive the moisture northward to converge in central China, offering abundant moisture supply for the increase of local precipitation.

The time series of the WIO-SST from 1961 to 2016 also reveals a transition in the 1990s from a cooling trend to a warming trend (Fig. 10). Based on the result from Fig. 9, the cooling polarity turning to the warming polarity in SST in the western Indian Ocean is beneficial for the autumn precipitation in central China switching from the decreasing trend to the increasing trend. No appreciable trend is detected for the SEIO-SST, which is characterized mainly by the interannual and interdecadal variability (figure not shown). This result indicates a disproportionally larger contribution to the trend
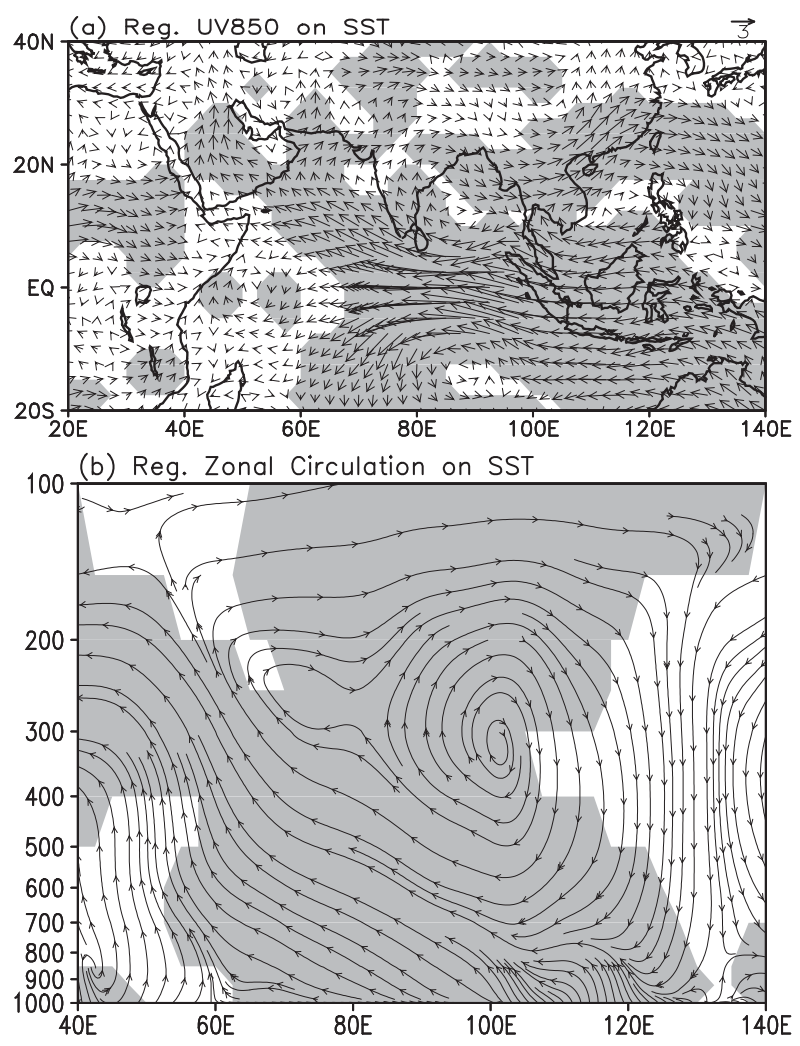

FIG. 9. Regressions of (a) the horizontal winds at $850 \mathrm{hPa}$ and (b) the meridional wind $\left(\mathrm{m} \mathrm{s}^{-1}{ }^{\circ} \mathrm{C}^{-1}\right)$ and vertical velocity $(0.5 \times$ $10^{-2} \mathrm{~Pa} \mathrm{~s}^{-1}{ }^{\circ} \mathrm{C}^{-1}$ ) along $10^{\circ} \mathrm{S}-10^{\circ} \mathrm{N}$ against the difference between WIO-SST and SEIO-SST. All data were detrended before calculating. Regions above the 95\% significance level are shaded.

transition of the autumn precipitation from the change in SST in the western Indian Ocean.

In total, the SST change from the cooling trend to the warming trend in the western Indian Ocean may induce anomalous lower-tropospheric easterlies over the tropical Indian Ocean through its influence on the local Walker circulation. Consequently, anomalous anticyclonic circulations reside on both sides of the equator. The anticyclonic anomaly to the north favors the southwesterly transportation of moisture to central China and contributes to the transition of the trend in autumn rainfall from a deceasing trend to an increasing trend.

\section{b. Atlantic Ocean SST}

Figure 11 shows the correlations between the SST in the Atlantic Ocean and the autumn precipitation averaged over central China. Two key regions $\left(30^{\circ}-50^{\circ} \mathrm{N}\right.$, $70^{\circ}-45^{\circ} \mathrm{W}$ and $45^{\circ}-60^{\circ} \mathrm{N}, 45^{\circ}-20^{\circ} \mathrm{W}$ ), are highlighted for the Atlantic Ocean SST, which are positively and negatively correlated to the autumn precipitation, respectively. 


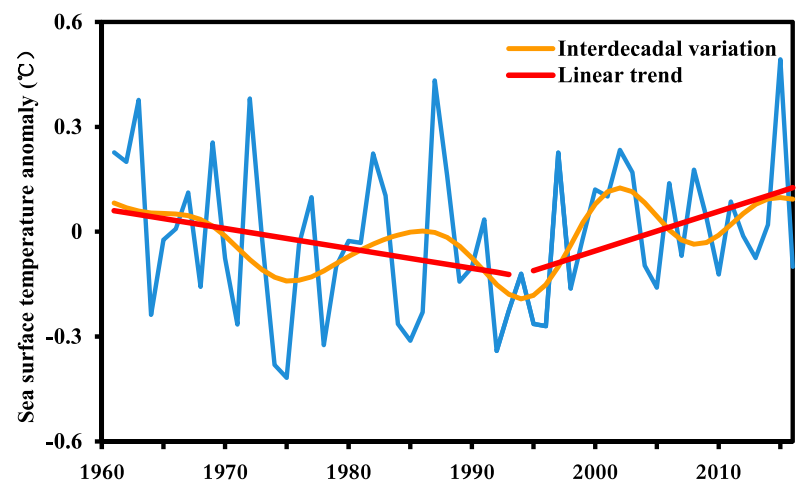

FIG. 10. Time series of the autumn SST anomaly in the western Indian Ocean $\left(10^{\circ} \mathrm{S}-10^{\circ} \mathrm{N}, 65^{\circ}-85^{\circ} \mathrm{E}\right)$ from 1961 to 2016.

If the SST anomalies are positive in the western Atlantic Ocean and negative in the eastern Atlantic Ocean, autumn precipitation tends to increase in central China, and vice versa. Thus, the mean SST in these two regions is defined as the indices (WAO-SST and EAO-SST) to measure the SST variation in the western and eastern Atlantic Ocean, respectively, for further analysis. Their difference (i.e., WAO-SST minus EAO-SST) is significantly correlated to autumn rainfall in central China, with the coefficients being 0.45 and 0.47 before and after detrending, respectively. Their correlation on the interdecadal time scale is 0.59 , exceeding the $99 \%$ significance level (Table 1).

To explore the physical mechanism responsible for the linkage of the Atlantic Ocean SST to the autumn precipitation in central China, we analyzed the anomalies in 500-hPa geopotential height regressed upon the WAO-SST and EAO-SST indices. The regression map indicates that associated with the warm WAO-SST is a well-organized wave train pattern featured by distinctly alternating positive-negative-positive-negative anomalies extending eastward from the Atlantic Ocean to Asia (Fig. 12a). Associated with the cold EAO-SST, a salient zonal-oriented teleconnection pattern is also observed with the negative-positive-negative anomalies emanating from the Atlantic Ocean to the Asian continent via Europe (Fig. 12b). The importance of the teleconnection wave train in bridging the Atlantic climate and the East Asian climate has been previously documented (Lu et al. 2002; Sun et al. 2008; Wu et al. 2012; Zhou 2013; Zhou and Cui 2014; Orsolini et al. 2015; Zhou and Wang 2015). With the aid of the teleconnection wave train, the SST signal can propagate downstream to the Asian continent and then impact local atmospheric circulations. More interestingly, the geopotential height anomalies related to the WAO-SST and the EAO-SST are in the same phase over the Asian continent where the Lake Balkhash trough is situated,

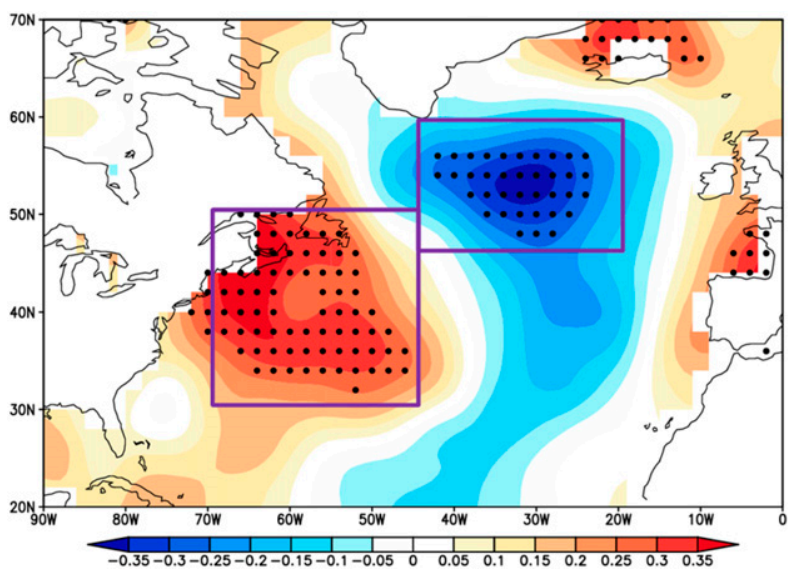

FIG. 11. Correlations between the SST in the Atlantic Ocean and the precipitation averaged over central China during autumn of 1961-2016. All data were detrended before calculating. Regions above the $95 \%$ significance level are marked by dots.

indicating a superimposed effect of the positive (negative) SST in the western (eastern) Atlantic Ocean. It is also noted that the negative height anomalies in the Asian continent related to the WAO-SST are much more significant and more eastward than the counterpart related to the EAO-SST.

Correspondingly, in the lower troposphere, the cyclonic circulation anomaly appears around Lake Balkhash, and the anticyclonic circulation anomaly emerges in the Arabian Sea to the Bay of Bengal in association with the warm WAO-SST (Fig. 13a). The deepened Lake Balkhash trough favors the southeastward invasion of cold air. The westerly and southwesterly airflow originating from the anomalous anticyclonic circulation in the Arabian Sea to the Bay of Bengal drive the moisture from the ocean northward. It yields the greatly sufficient moisture supply and more intense interaction over central China with the cold air coming from high latitudes, which is expected to increase local precipitation. Because of relatively weaker propagation of the wave train related to the EAO-SST than to the WAO-SST, the above atmospheric circulation anomalies corresponding to the EAO-SST change are less pronounced and westward (Fig. 13b).

Figure 14 presents the change of the WAO-SST and EAO-SST. For the western Atlantic Ocean, the SST exhibits a cooling trend before the late 1990s and switches to a warming trend after the late 1990s, which conforms to the change in autumn precipitation over central China from the decreasing trend to the increasing trend. For the eastern Atlantic Ocean, the SST decreases before the 1990s, increases from the 1990s to the 2000s, and then decreases again. Note that the 

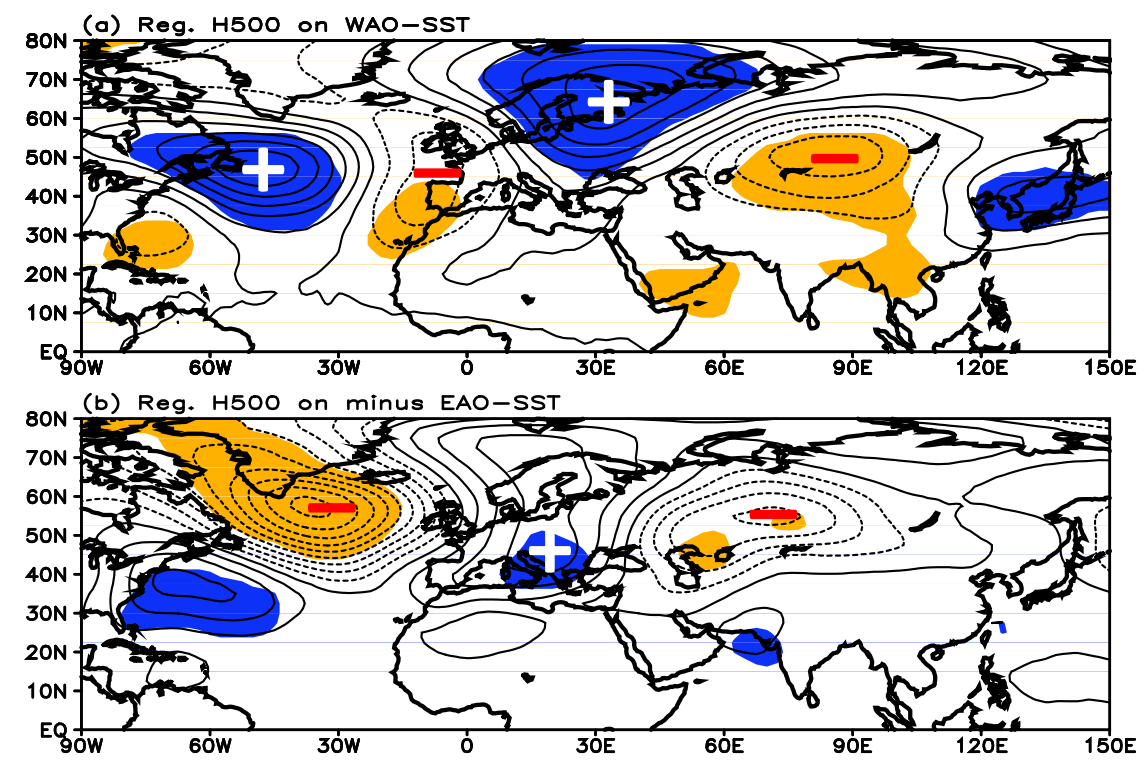

FIG. 12. Regressions of the geopotential height at $500 \mathrm{hPa}\left(10 \mathrm{~m}^{\circ} \mathrm{C}^{-1}\right)$ against (a) WAO-SST and (b) minus EAO-SST. All data were detrended before calculating. Regions above the $95 \%$ significance level are shaded.

decrease (increase) in SST in this region may increase (decrease) the autumn precipitation in central China. Thus, the in-phase changes in SST between the eastern and western Atlantic Ocean from the 1960s to the mid2000s have an abating contribution to the decreasing trend of the autumn precipitation, while their out-ofphase change in SST after the mid-2000s tends to accelerate the increase of autumn precipitation.

To put it simply, the interdecadal variation of the SST in the Atlantic Ocean motivates the anomalous wave train from the Atlantic Ocean to the Asian continent via Europe. As a consequence, the Lake
Balkhash trough is deepened. The deepened trough is beneficial for the southeastward invasion of cold air to central China, thereby favoring the change of local autumn rainfall from the decreasing trend to the increasing trend.

From the above analyses, it is interesting to find that the interdecadal variation of the SST in the tropical Indian Ocean intensifies the southwesterly moisture transport through affecting tropical circulations, while the interdecadal variation of the SST in the Atlantic Ocean enhances the cold-air activity by changing atmospheric circulations in the mid- to high latitudes.
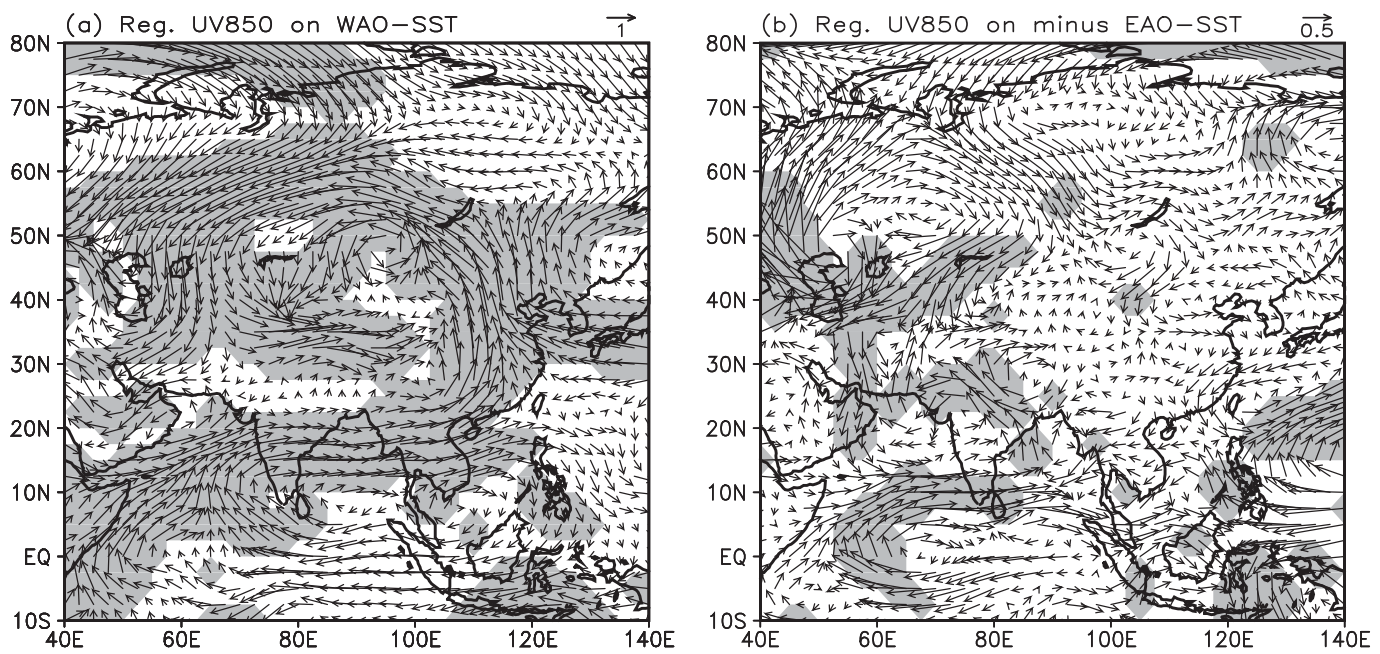

FIG. 13. As in Fig. 12, but for regressions of the horizontal winds at $850 \mathrm{hPa}$. 

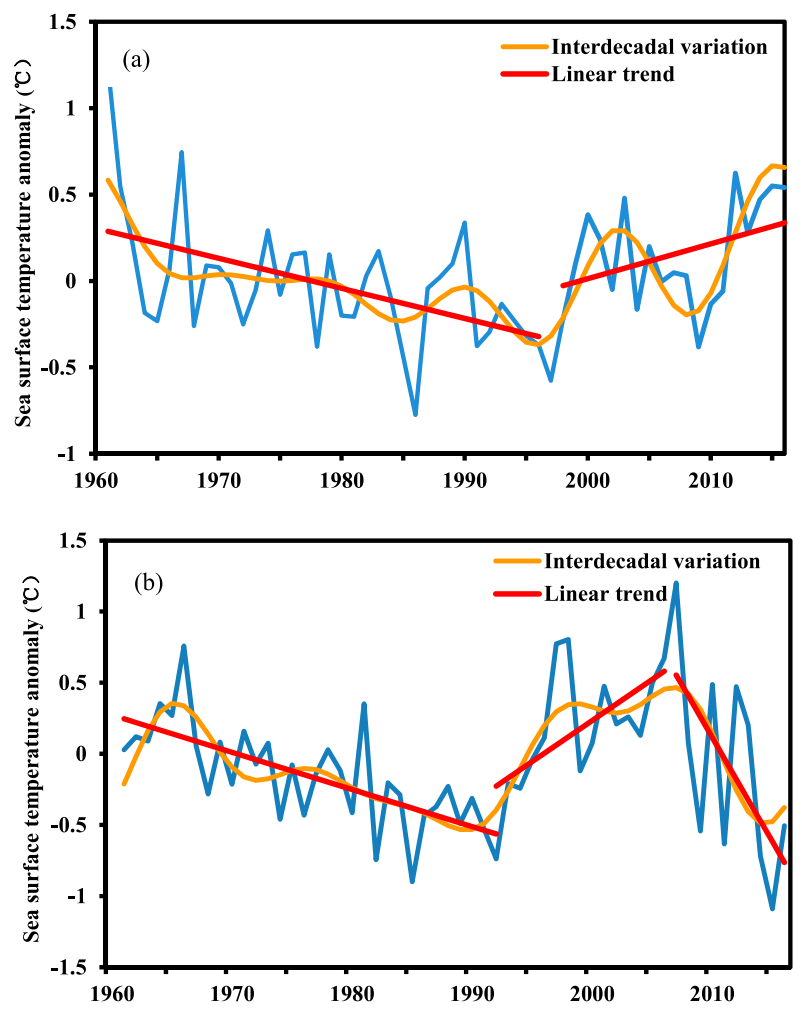

FIG. 14. Time series of the autumn SST anomaly in (a) the western Atlantic Ocean $\left(30^{\circ}-50^{\circ} \mathrm{N}, 70^{\circ}-45^{\circ} \mathrm{W}\right)$ and (b) the eastern Atlantic Ocean $\left(45^{\circ}-60^{\circ} \mathrm{N}, 45^{\circ}-20^{\circ} \mathrm{W}\right)$ from 1961 to 2016.

\section{Conclusions}

Based on the daily gauged precipitation data for the period of 1961-2016, this study has shown a transition in the late 1990s for the trend of autumn rainfall over central China. During the former period, the autumn rainfall exhibits a decreasing trend. However, it shifts to an increasing trend during the latter period. This regime shift can also be observed in the trend of the amounts of light to heavy rainfall events.

The possible mechanism responsible for the above regime shift is preliminarily identified from the perspective of changes in local moisture and dynamic conditions, large-scale atmospheric circulations, and SSTs in key ocean regions. First, the shift from a weakening trend to a strengthening trend in both moisture convergence and vertically ascending motion in the late 1990s accounts for the trend transition of autumn rainfall in central China.

Second, the large-scale circulations associated with the increased autumn rainfall in central China include the negative SLP anomaly in Asia, the deep trough around Lake Balkhash, the southerly anomaly in the lower troposphere of East Asia, and the northward displacement of the EAJ location. The declining of SLP

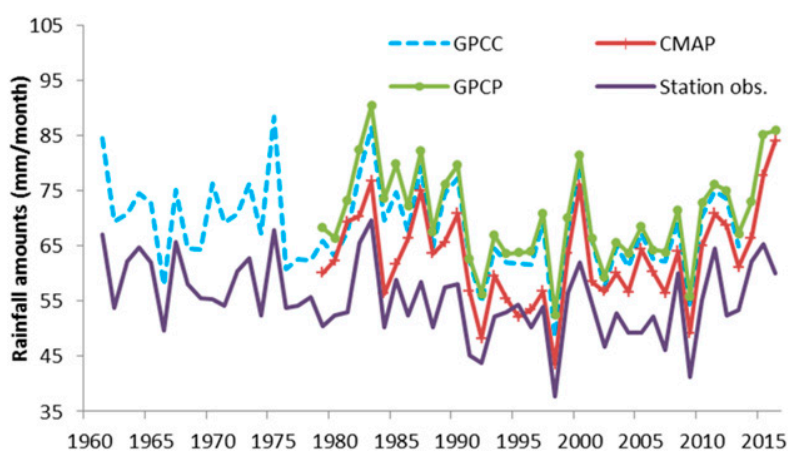

FIG. 15. Time series of autumn rainfall in central China derived from different datasets.

in Asia and the deepening of the Lake Balkhash trough, concurrent with the intensifying of the southerly in East Asia, enables more cold air from high latitudes and more warm, moist airflow from low latitudes to enter central China, consequently producing the increasing trend of local precipitation since the late 1990s. The EAJ movement from south to north may also have a contribution.

Last but not least is the role of the SSTs in the Indian and Atlantic Oceans. The warmer SST in the western Indian Ocean may lead to more rainfall in central China by evoking anomalous anticyclonic circulation in the Arabian Sea to the Bay of Bengal, which helps to deliver the moisture to the targeted region. The SST warming in the western Atlantic Ocean may enhance autumn rainfall in central China through the downstream propagation of the signal via wave train teleconnection, which consequently results in more intense interaction between cold air from high latitudes and warm, moist airflow from low latitudes in the targeted region. Thus, the SST changes in the western Indian Ocean and the western Atlantic Ocean from a cooling trend to a warming trend in the late 1990s are responsible for the shift of autumn rainfall from a decreasing trend to an increasing trend.

For the solid foundation, we verified the change of autumn rainfall in central China by using other popular grid precipitation datasets, including the CPC Merged Analysis of Precipitation (CMAP; Xie and Arkin 1997), monthly land surface precipitation from rain gauges built on GTS-based and historic data from the Global Precipitation Climatology Centre (Schneider et al. 2011), and the GPCP version 2.3 combined precipitation dataset (Adler et al. 2003). These datasets all indicate a decadal transition in the late 1990s for the trend of autumn rainfall (Fig. 15), consistent with the result obtained from the meteorological stations in China. While there are strong correlations among these different time series, we also note some differences in 
the long-term changes. Moreover, the year-to-year variations are much larger than the long-term changes. Thus, the trends are not very robust, compared with the interannual variability. In addition, the autumn precipitation also shows interdecadal variability, which is speculated to be related to decadal signals of atmosphereocean system, such as AMO phase changes. This issue will be addressed in our future research. Another issue we should keep in mind is the reliability of reanalysis data to study long-term trend/change. It has been pointed out that various biases and inhomogeneity problems exist in reanalysis data; for instance, the moisture and some other upper-air fields in the NCEP-NCAR reanalysis may contain artificial changes (Dai et al. 2011, 2013). They are thus best used for investigating the spatial and short-term (seasonal to multiyear) variation (Wu et al. 2005). So, we should be cautious with the results. Although the consistency between the grid datasets and the station dataset, as well as the dynamic consistency between changes in precipitation and changes in different atmospheric circulations and SSTs, justifies the findings in this study and, to a certain degree, validate the reliability of the reanalysis datasets for this study, more analyses are still needed in the future to provide more robust evidence.

Acknowledgments. This research was jointly supported by the National Natural Science Foundation of China (Grant 41675069), the National Key Research and Development Program of China (Grants 2016YFA0600701 and 2018YFA0606301), the Startup Foundation for Introducing Talent of NUIST, and the National Program for Support of Top-Notch Young Professionals.

\section{REFERENCES}

Adler, R. F., and Coauthors, 2003: The Version-2 Global Precipitation Climatology Project (GPCP) Monthly Precipitation Analysis (1979-present). J. Hydrometeor., 4, 1147-1167, https://doi.org/ 10.1175/1525-7541(2003)004<1147:TVGPCP >2.0.CO;2.

Bai, H., and W. Dong, 2004: Climate features and formation causes of autumn rain over southwest China. Plateau Meteor., 23, 884-889.

Bao, Y., L. F. Abulimiti, and X. Wang, 2003: Space-time distribution and physical mechanisms of autumn rains in west China in 2001. J. Appl. Meteor. Sci., 14, 215-222.

Bretherton, C. S., M. Widmann, V. P. Dymnikov, J. M. Wallace, and I. Blade, 1999: The effective number of spatial degrees of freedom of a time-varying field. J. Climate, 12, 1990-2009, https://doi.org/ 10.1175/1520-0442(1999)012<1990:TENOSD>2.0.CO;2.

Cao, L., Y. Zhu, G. Tang, F. Yuan, and Z. Yan, 2016: Climatic warming in China according to a homogenized data set from 2419 stations. Int. J. Climatol., 36, 4384-4392, https://doi.org/ 10.1002/joc. 4639

Chang, C. P., Y. Zhang, and T. Li, 2000: Interannual and interdecadal variations of the East Asian summer monsoon and tropical Pacific SSTs. Part I: Roles of the subtropical ridge. J. Climate, 13, 4310-4325, https://doi.org/10.1175/ 1520-0442(2000)013<4310:IAIVOT > 2.0.CO;2.

Chen, Y., and N. Shi, 2003: Spatial and temporal distribution of autumn precipitation and temperature in China and climatic change. J. Nanjing Inst. Meteor., 26, 622-630.

Chen, Z., F. Liu, P. Zhao, and Z. Ma, 2001: Relationship between the surface heating fields over Qinghai-Xizang Plateau and precipitation of southwest China in autumn. Plateau Meteor., 20, 94-99.

Dai, A., J. Wang, P. W. Thorne, D. E. Parker, L. Haimberger, and X. L. Wang, 2011: A new approach to homogenize daily radiosonde humidity data. J. Climate, 24, 965-991, https:// doi.org/10.1175/2010JCLI3816.1.

- - H. Li, Y. Sun, L.-C. Hong, LinHo, C. Chou, and T. Zhou, 2013: The relative roles of upper and lower tropospheric thermal contrasts and tropical influences in driving Asian summer monsoons. J. Geophys. Res. Atmos., 118, 7024-7045, https://doi.org/10.1002/jgrd.50565.

Davis, R. E., 1976: Predictability of sea surface temperature and sea level pressure anomalies over the North Pacific Ocean. J. Phys. Oceanogr., 6, 249-266, https://doi.org/10.1175/ 1520-0485(1976)006<0249:POSSTA $>2.0$.CO;2.

Ding, Y., 2007: The variability of the Asian summer monsoon. J. Meteor. Soc. Japan, 85B, 21-54, https://doi.org/10.2151/ jmsj.85B.21.

- and Z. Wang, 2008: A study of rainy seasons in China. Meteor. Atmos. Phys., 100, 121-138, https://doi.org/10.1007/ s00703-008-0299-2.

,-- , and Y. Sun, 2008: Inter-decadal variation of the summer precipitation in East China and its association with decreasing Asian summer monsoon. Part I: Observed evidences. Int. J. Climatol., 28, 1139-1161, https://doi.org/10.1002/joc.1615.

, Y. Sun, Z. Wang, Y. Zhu, and Y. Song, 2009: Inter-decadal variation of the summer precipitation in China and its association with decreasing Asian summer monsoon. Part II: Possible causes. Int. J. Climatol., 29, 1926-1944, https://doi.org/ 10.1002/joc.1759.

Fan, K., Z. Xu, and B. Tian, 2014: Has the intensity of the interannual variability in summer rainfall over South China remarkably increased? Meteor. Atmos. Phys., 124, 23-32, https:// doi.org/10.1007/s00703-013-0301-5.

Fu, J., S. Li, and D. Luo, 2009: Impact of global SST on decadal shift of East Asian summer climate. Adv. Atmos. Sci., 26, 192-201, https://doi.org/10.1007/s00376-009-0192-z.

Gao, Y., and Q. Guo, 1958: On the autumn raining area in China. Acta Meteor. Sin., 29, 264-273.

Gong, D., and C. H. Ho, 2002: Shift in the summer rainfall over the Yangtze River valley in the late 1970s. Geophys. Res. Lett., 29, 1436, https://doi.org/10.1029/2001GL014523.

Guan, Z., and T. Yamagata, 2003: The unusual summer of 1994 in East Asia: IOD teleconnection. Geophys. Res. Lett., 30, 1544, https://doi.org/10.1029/2002GL016831.

He, M., 1984: Distribution and long-term forecast of Chinese autumn rainfalls. Meteor. Mon., 10, 10-13.

Hu, Z., 1997: Interdecadal variability of summer climate over East Asia and its association with $500 \mathrm{hPa}$ height and global sea surface temperature. J. Geophys. Res., 102, 19403-19412, https://doi.org/10.1029/97JD01052.

Huang, D., A. Dai, J. Zhu, Y. Zhang, and X. Kuang, 2017: Recent winter precipitation changes over eastern China in different warming periods and the associated East Asian jets and oceanic conditions. J. Climate, 30, 4443-4462, https://doi.org/ 10.1175/JCLI-D-16-0517.1. 
Huang, R., Y. Liu, and T. Feng, 2013: Interdecadal change of summer precipitation over eastern China around the late1990s and associated circulation anomalies, internal dynamical causes. Chin. Sci. Bull., 58, 1339-1349, https://doi.org/ 10.1007/s11434-012-5545-9.

Jiang, Z., Z. Ma, J. Liu, and Q. Li, 2014: Improved index and climatological characteristics of the autumn rain in western China. Chin. J. Atmos. Sci., 38, 32-44.

Kalnay, E., and Coauthors, 1996: The NCEP/NCAR 40-year reanalysis project. Bull. Amer. Meteor. Soc., 77, 437-472, https:// doi.org/10.1175/1520-0477(1996)077<0437:TNYRP>2.0.CO;2.

Li, C., and M. Mu, 2001: The dipole in the equatorial Indian Ocean and its impacts on climate. Chin. J. Atmos. Sci., 25, 433-443.

- , and P. Xian, 2003: Atmospheric anomalies related to interdecadal variability of SST in the North Pacific. Adv. Atmos. Sci., 20, 859-874, https://doi.org/10.1007/BF02915510.

Li, S., J. Lu, G. Huang, and K. Hu, 2008: Tropical Indian Ocean basin warming and East Asian summer monsoon: A multiple AGCM study. J. Climate, 21, 6080-6088, https://doi.org/ 10.1175/2008JCLI2433.1.

Liang, J., 1989: The regional and seasonal distribution of autumn rain in west China. Sci. Geogr. Sin., 9, 51-59.

Liu, X., and M. Yanai, 2002: Influence of Eurasian spring snow cover on Asian summer rainfall. Int. J. Climatol., 22, 10751089, https://doi.org/10.1002/joc. 784 .

— between IOD and autumn rainfall in China. J. Nanjing Inst. Meteor., 29, 762-768.

Liu, Y., L. Sun, C. Sun, Z. Wang, Y. Wang, and Y. Yuan, 2012: Analysis of anomalies of autumn rain in West China in 2011. Meteor. Mon., 38, 456-463.

Lu, R., J. H. Oh, and B. J. Kim, 2002: A teleconnection pattern in upper-level meridional wind over the North African and Eurasian continent in summer. Tellus, 54A, 44-55, https:// doi.org/10.3402/tellusa.v54i1.12122.

— B. Bong, and H. Ding, 2006: Impact of the Atlantic multidecadal oscillation on the Asian summer monsoon. Geophys. Res. Lett., 33, L24701, https://doi.org/10.1029/2006GL027655.

Luo, X., D. Li, and H. Wang, 2013: New evolution features of autumn rainfall in West China and its responses to atmospheric circulation. Plateau Meteor., 32, 1019-1031.

Ma, Z., 2007: The interdecadal trend and shift of dry/wet over the central part of North China and their relationship to the Pacific decadal oscillation (PDO). Chin. Sci. Bull., 52, 2130-2139, https://doi.org/10.1007/s11434-007-0284-z.

Orsolini, Y. J., L. Zhang, D. H. W. Peters, K. Fraedrich, X. Zhu, A. Schneidereit, and B. van den Hurk, 2015: Extreme precipitation events over North China in August 2010 and their link to eastward-propagating wave-trains across Eurasia: Observations and monthly forecasting. Quart. J. Roy. Meteor. Soc., 141, 3097-3105, https://doi.org/10.1002/qj.2594.

Qian, W., and A. Qin, 2008: Precipitation division and climate shift in China from 1960 to 2000. Theor. Appl. Climatol., 93, 1-17, https://doi.org/10.1007/s00704-007-0330-4.

Qin, M., D. Li, A. Dai, W. Hua, and H. Ma, 2018: The influence of the Pacific decadal oscillation on north central China precipitation during boreal autumn. Int. J. Climatol., 38, e821e831, https://doi.org/10.1002/joc.5410.

Saji, N. H., B. N. Goswami, P. N. Vinayachandran, and T. Yamagata, 1999: A dipole mode in the tropical Indian Ocean. Nature, 401, 360-363, https://doi.org/10.1038/43854.

Schneider, U., A. Becker, P. Finger, M. C. Anja, B. Rudolf, and M. Ziese, 2011: GPCC full data reanalysis version 6.0 at $1.0^{\circ}$ :
Monthly land-surface precipitation from rain-gauges built on GTS-based and historic data. Federal Ministry of Transport and Digital Infrastructure, accessed January 2018, https://doi.org/ 10.5676/DWD_GPCC/FD_M_V6_100.

Smith, T. M., and R. W. Reynolds, 2004: Improved extended reconstruction of SST (1854-1997). J. Climate, 17, 2466-2477, https://doi.org/10.1175/1520-0442(2004)017<2466: IEROS $>2.0 . \mathrm{CO} ; 2$.

Sun, J., H. Wang, and W. Yuan, 2008: Decadal variations of the relationship between the summer North Atlantic Oscillation and middle East Asian air temperature. J. Geophys. Res., 113, D15107, https://doi.org/10.1029/2007JD009626.

Wang, C., Z. Ma, J. Wang, and J. Wang, 2015: The characteristics of Huaxi autumn rain and its relationship with sea surface temperatures over the equatorial Pacific. Chin. J. Atmos. Sci., 39, 643-652.

Wang, H., 2001: The weakening of the Asian monsoon circulation after the end of 1970's. Adv. Atmos. Sci., 18, 376-386, https:// doi.org/10.1007/BF02919316.

Wang, T., H. Wang, O. H. Otterå, Y. Gao, L. Suo, T. Furevik, and L. Yu, 2013: Anthropogenic agent implicated as a prime driver of shift in precipitation in eastern China in the late 1970s. Atmos. Chem. Phys., 13, 12 433-12 450, https://doi.org/ 10.5194/acp-13-12433-2013.

Wu, B., K. Yang, and R. Zhang, 2009: Eurasian snow cover variability and its association with summer rainfall in China. Adv. Atmos. Sci., 26, 31-44, https://doi.org/10.1007/ s00376-009-0031-2.

Wu, R., and L. Chen, 1998: Decadal variation of summer rainfall in the Yangtze-Huaihe River valley and its relationship to atmospheric circulation anomalies over East Asia and western North Pacific. Adv. Atmos. Sci., 15, 510-522, https://doi.org/ 10.1007/s00376-998-0028-2.

_ J. L. Kinter III, and B. P. Kirtman, 2005: Discrepancy of interdecadal changes in the Asian region among the NECP-NCAR reanalysis, objective analyses, and observations. J. Climate, 18, 3048-3067, https://doi.org/10.1175/JCLI3465.1.

_ Z Z. Wen, S. Yang, and Y. Li, 2010: An interdecadal change in southern China summer rainfall around 1992/93. J. Climate, 23, 2389-2403, https://doi.org/10.1175/2009JCLI3336.1.

Wu, Z., J. Li, Z. Jiang, J. He, and X. Zhu, 2012: Possible effects of the North Atlantic Oscillation on the strengthening relationship between the East Asian summer monsoon and ENSO. Int. J. Climatol., 32, 794-800, https://doi.org/10.1002/joc.2309.

Xie, P., and P. A. Arkin, 1997: Global precipitation: A 17-year monthly analysis based on gauge observations, satellite estimates, and numerical model outputs. Bull. Amer. Meteor. Soc., 78, 2539-2558, https://doi.org/10.1175/1520-0477(1997)078<2539: GPAYMA $>2.0 . \mathrm{CO} ; 2$.

Xu, K., C. Zhu, and W. Wang, 2016: The cooperative impacts of the El Niño-Southern Oscillation and the Indian Ocean dipole on the interannual variability of autumn rainfall in China. Int. J. Climatol., 36, 1987-1999, https://doi.org/10.1002/joc.4475.

Xu, Z., K. Fan, and H. Wang, 2015: Decadal variation of summer precipitation over China and associated atmospheric circulation after the late 1990s. J. Climate, 28, 4086-4106, https:// doi.org/10.1175/JCLI-D-14-00464.1.

Yang, F., and K. M. Lau, 2004: Trend and variability of China precipitation in spring and summer: Linkage to sea surface temperatures. Int. J. Climatol., 24, 1625-1644, https://doi.org/ 10.1002/joc.1094.

Yao, C., S. Yang, W. Qian, Z. Lin, and M. Wen, 2008: Regional summer precipitation events in Asia and their changes in the 
past decades. J. Geophys. Res., 113, D17107, https://doi.org/ 10.1029/2007JD009603.

Yu, R., B. Wang, and T. Zhou, 2004: Tropospheric cooling and summer monsoon weakening trend over East Asia. Geophys. Res. Lett., 31, L22212, https://doi.org/10.1029/2004GL021270.

Yuan, X., and X. Liu, 2013: Onset-withdrawal dates of autumn persistent rains over West China and the associated autumn to winter evolution of the atmospheric circulation. Acta Meteor. Sin., 71, 913-924.

Zhang, C., Z. Wang, B. Zhou, Y. Li, H. Tang, and B. Xiang, 2018: Trends in autumn rain of West China from 1961 to 2014. Theor. Appl. Climatol., https://doi.org/10.1007/s00704-017-2361-9, in press.

Zhang, R., B. Wu, P. Zhao, and J. Han, 2008: The decadal shift of the summer climate in the late 1980s over Eastern China and its possible causes. Acta Meteor. Sin., 22, 435-445.

Zhang, Y., T. Li, and B. Wang, 2004: Decadal change of the spring snow depth over the Tibetan Plateau: The associated circulation and influence on the East Asian summer monsoon. J. Climate, 17, 2780-2793, https://doi.org/10.1175/ 1520-0442(2004)017<2780:DCOTSS >2.0.CO;2.

Zhao, P., S. Yang, and R. Yu, 2010: Long-term changes in rainfall over eastern China and large-scale atmospheric circulation associated with recent global warming. J. Climate, 23, 15441562, https://doi.org/10.1175/2009JCLI2660.1.

- _ - H. Wang, and Q. Zhang, 2011: Interdecadal relationships between the Asian-Pacific oscillation and summer climate anomalies over Asia, North Pacific, and North America during a recent 100 years. J. Climate, 24, 4793-4799, https:// doi.org/10.1175/JCLI-D-11-00054.1.

Zhou, B., 2013: Weakening of winter North Atlantic Oscillation signal in spring precipitation over southern China. Atmos. Ocean. Sci. Lett., 6, 248-252, https://doi.org/10.1080/ 16742834.2013.11447089.

— , and X. Cui, 2014: Interdecadal change of the linkage between the North Atlantic Oscillation and the tropical cyclone frequency over the western North Pacific. Sci. Chin. Earth Sci., 57, 2148-2155, https://doi.org/10.1007/s11430-014-4862-z.

- , and Z. Wang, 2015: On the significance of the interannual relationship between the Asian-Pacific Oscillation and the North Atlantic Oscillation. J. Geophys. Res. Atmos., 120, 6489-6499, https://doi.org/10.1002/2015JD023328.

Zhu, Y., H. Wang, W. Zhou, and J. Ma, 2011: Recent changes in the summer precipitation pattern in East China and the background circulation. Climate Dyn., 36, 1463-1473, https:// doi.org/10.1007/s00382-010-0852-9. 